\title{
The rising damp tests of Camberwell Pier: Potential height of moisture rise in brickwork and the effectiveness of a modern chemical injection cream damp coursing application
}

Received (in revised form): 24th May 2010

\section{Ralph Burkinshaw}

is a chartered building surveyor, visiting lecturer and independent dampness consultant. He carries out investigations all over the United Kingdom, whenever a professional opinion is sought on the cause of dampness or suitable remediation.

Correspondence: Ralph Burkinshaw, 32 Acland Crescent, London, SE5 8EQ, UK

E-mail: rf.burkinshaw2@ukonline.co.uk;

Web: www.damp-diagnosis.co.uk

Journal of Building Appraisal (2010) 6, 5-19. doi:10.1057/jba.2010.13

What I cannot create, I do not understand. Richard Feynman (American Physicist, 1918-1988)

\section{INTRODUCTION}

It has to be said at the outset that any masonry pier standing in a tray of water, such as Camberwell Pier, cannot by commonly accepted definition be subject to 'rising damp'. Rising damp has to be ground sourced. So a rise of moisture in a brick pier cannot prove or disprove the existence of rising damp as a phenomena. The tests that follow should shed light on how high moisture can rise in masonry, and whether a chemical injection damp proof course $(\mathrm{dpc})$ could potentially halt that rise. The author also wishes to set the scene by clarifying various terms relevant to low-level dampness in buildings. Any discussions concerning dampness in buildings or indeed any other subject can only be meaningful when those involved agree on, or are at least aware of, the meanings or accepted industry definitions of keywords and terminology used. Definitions of words and terms form the cornerstone of language. As readers will appreciate, there is a little confusion in the industry concerning exactly what 'rising damp' is. This is mainly because the Building Research Establishment (BRE) have not yet in the author's opinion carefully and adequately defined it. There is very little independent published advice concerning diagnosis and remediation of wallbase damp problems.

\section{Examples of description/definitions of rising damp in recent times} 1970s-1980s

Melville and Gordon (1998) consider that: 'Ground water reaching the foot of a wall will, therefore, tend to rise in the walling materials and will continue to do so due to capillary action to varying degrees of intensity. This penetration of ground moisture is commonly known as rising dampness ...'. 
Oxley and Gobert (1989) also link rising damp to the ground: 'Rising Dampness results from capillary flow of water from the ground'.

2003

In Diagnosing Damp (Burkinshaw and Parrett, 2003), 'Rising Damp' is defined more comprehensively as moisture that 'travels upwards through the pore structure, or via small fissures or cracks, or as water vapour, against the forces of gravity, typically up a wall or though a floor from a source below the ground'.

2004

In Understanding Dampness (Trotman et al, 2004), a briefish definition is offered by the BRE as follows: "normally the upward transfer of moisture in a porous material due to capillary action'.

There is no mention here of a ground source.

2007

The BRE publish a new edition of BRE245 (BRE, 2007), but still do not actually define the subject of the re-issued Digest. An early paragraph refers to walls that 'stand in water or saturated soils'. This infers that a low-level penetrating damp could also be 'rising damp' and therefore that Camberwell Pier could, according to the BRE, be experiencing rising damp. But the later parts of the Digest focus on how to assess source of dampness by analysis of role of hygroscopic salts - which would be mainly sourced from the ground.

2009

For this author and probably most other writers and researchers, wallbase damp (defined in Remedying Damp - Burkinshaw, 2009) must involve a significant amount of moisture sourced from the ground - to be 'rising damp'. Rising damp from the ground is sometimes referred to as 'true rising damp'. Rising damp usually presents itself by salty yellowy browny patches of plaster/decor just above skirting board height.

\section{Low-level penetrating damp}

The author believes that more thorough survey work would result in fewer walls being diagnosed as having 'rising damp', with many more diagnosed as subject to 'low-level penetrating damp' - LLPD. This is here defined as:

Where dampness enters the base of the external wall face at or just above external ground/yard level, to then pass mainly laterally through the wall structure to usually dampen internal fabric, finishes or components. The low level damp penetration may be above or below the wall dpc.

Such a damp penetration is often caused by a 'ledge effect'. This is defined by Ralph F. Burkinshaw (2009) as follows:

penetrating dampness at any level on the external envelope, caused by pooling or splashing or impinging of (usually) rainwater at the junction of a horizontal surface to the vertical wall surface - being most common at the wallbase.

As hard landscaping around a building rises over the years from successive re-surfacings, the 'ledge' rises, meaning that soaking of the wallbase impinges higher and higher up the wallbase, so the wet band rises upwards to cause more damage to 
skirting boards, plasters, built in timber etc. Application of impervious finishes to walls also helps drive moisture upwards.

A 'ledge effect' can also occur when the top of a boundary wall abuts an external wall.

Some wallbase damp problems can arise from a combination of sources, where for example there is both rising damp and low-level penetrating damp. And sometimes also some internal condensation. Moisture can rise up a wall within the wall's thickness, via the wall's finishes, or both.

In the author's experience, having taken drill samples and undertaken analysis of hundreds and hundreds of buildings, $L L P D$ is very often the driver, the 'lead source'. Remedies for LLPD do not usually need to incorporate a retro-fit dpc, although an internal masking plaster system can often be effective, especially if changes to outside landscaping cannot be made for technical, budgetary or legal reasons. Some masking plaster systems can incorporate air gaps to help control wallbase damp.

Examples of remedies for LLPD can be found in Chapter 5 of the author's work (Burkinshaw, 2009).

And remember too that Rising damp does not just affect walls as some seem to suggest. If you find that a solid ground-bearing floor has developed damp patches, for example because of lack of an adequate damp proof membrane underneath, then that floor will be subject to rising damp. The remedy could be laying new screed on a damp proof membrane. It is often possible to confirm such a rising damp (beyond doubt) by destructive testing - when, for example, hacked-up solid flooring is exposed wet underneath from contact with wet ground conditions.

\section{SOME FURTHER MISUNDERSTANDINGS EXPLAINED}

\section{Misunderstandings concerning the rise of moisture in masonry}

Opinion on how high moisture can rise in masonry ranges from just a course or two of masonry (for example, brickwork) to a dampness rise from ground level to first floor level - that is $2-3 \mathrm{~m}$. The author believes that if more surveyors actually measured moisture content deeper within building elements there would be less 'opinion' and more confirmed findings.

In the 1999 BBC2 documentary 'Raising the Roof: Rising Damp' (BBC2, 1999), research conducted at South Bank University was featured, where a number of brick piers had been allowed to stand in water trays for a prolonged period. The researcher had apparently not been able to produce (or identify) a significant rise of moisture in any of the piers. He also explained how the BRE had devised special mortars to replicate the kind of mortar found in old walls, but that even using such mortar, producing significant 'rising damp' was found to be very difficult. (As explained earlier, test piers in trays cannot in any case replicate rising damp.) The BBC2 documentary raised some important and valid issues concerning wallbase damp and how it can be diagnosed and remedied. However, some statements made in the documentary led some surveyors to doubt the very existence of 'rising damp'.

The reality is that every porous structure that sits on or in damp, wet or saturated ground will have 'rising damp' to an extent. The basic laws of physics dictate that, but in most cases, the rise of moisture will either be stopped or controlled by damp coursing or other influences, or will not rise significantly high enough or far enough to damage vulnerable fabric or finishes. You would not expect to find the first masonry course or two of any British building to be air dry. This would require it to be built isolated from the ground off a concrete raft or off stilts. 
So when it is questioned whether any building is subject to rising damp, we really mean significant rising damp. 'Significant Dampness' is defined in Diagnosing Damp (Burkinshaw and Parrett, 2003). Professor Hollis, in the standard surveyor's text Surveying Buildings (Hollis, 2005) countered the sceptics by offering the pragmatic opinion that 'rising dampness exists'. However, he did not actually offer a case of confirmed rising damp, but described a flooded property that suffered dampness rising in walls to $300 \mathrm{~mm}$. One of the problems here is that when a wallbase is subjected to a water load, moisture could actually be rising higher within the wall than is apparent from visual observation.

In Remedying Damp this author showed a good example of a hidden but high moisture rise within an inner solid wall of a London townhouse. Please refer to Case Study 2 'Dampness Will Out'. In that particular case, RFB confirmed (from careful building appraisal, drill sampling and salts analysis) a moisture rise of $1.7 \mathrm{~m}$ when both sides of inner masonry walls were coated with Synthaprufe up to $1 \mathrm{~m}$ height and hard rendered above to full height. In the author's opinion this moisture rise involved a below ground moisture source, that is, 'rising damp' (Burkinshaw, 2009).

\section{Misunderstandings concerning the effectiveness of chemical injection dpcs}

As fully explained in Remedying Damp, most BBA-certified chemical injection damp coursing systems comprise the injection plus the protective shield of new damp-resistant internal plastering - usually to a height of 1-1.2 $\mathrm{m}$ above floor level. Chemical injection damp coursing is therefore a 'combined remedy' (Burkinshaw, 2009). The effectiveness of the chemical injection itself might be difficult to determine - and it is only usually possible to assess the standard and effectiveness of the internal plaster masking. Graham Coleman (1990) considers that chemical dpc injection of masonry walls controls rather than stops moisture rise. This is also how some manufacturers of chemical injection systems describe the injection itself. In Surveying Buildings, Hollis expresses doubt concerning whether a chemical injection dpc can work, and that a healthy dose of scepticism should be applied to walls where a chemical injection damp course has been injected (Hollis, 2005).

Chartered surveyors generally seem to be becoming increasingly sceptical too. In spite of this growing doubt, chemical injection dpcs are still commonly specified, possibly because of a lack of published alternative remedies, and the comfort zone an attached damp proofer's guarantee provides. Many cases of damp proofing failure are not successfully challenged - because few chartered surveyors have the skills to competently assess the adequacy of the chemical injection or more importantly its associated plasterwork. Some examples of dpc plaster failure are illustrated by colour plates in Remedying Damp (Burkinshaw, 2009). This test should shed some light on the potential effectiveness of a modern chemical injection procedure.

\section{MOISTURE RISE TEST ON CAMBERWELL PIER}

\section{Setting up the brick pier test}

\section{Building the pier}

The mortar for Camberwell Pier contained mainly sharp sand with a small proportion of soft 'building sand', and Castle Natural Hydraulic Lime. Sand was from Borough Green 


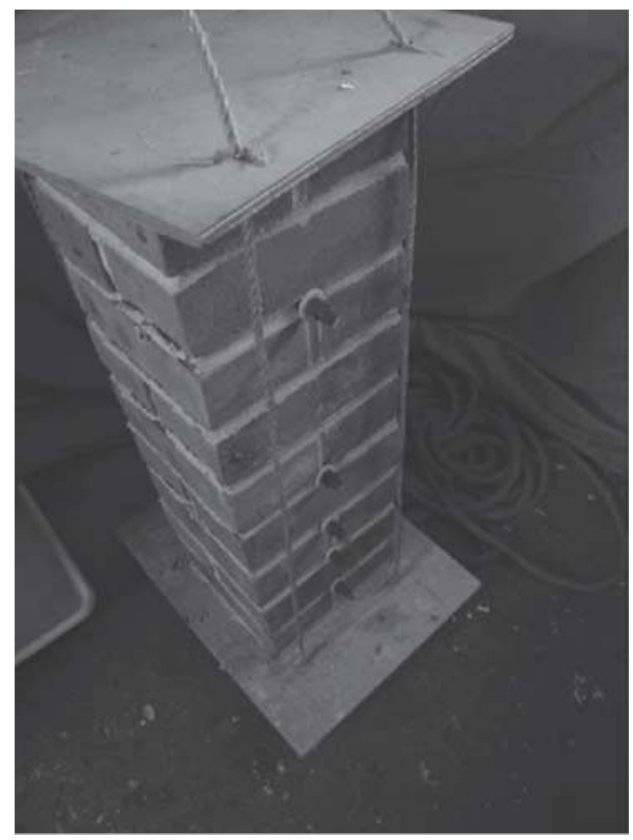

Having stood idle for three years in a covered workshop, Camberwell Pier is about to take a dip. All the lime mortar joints are pristine snow white. The pier can be lifted for weighing by a simple rope pulley system. The five electronic sensors will soon be registering dampness rising up within the masonry.

Perhaps the height of the upper sensor showed a certain degree of optimism.

Figure I: Pier on plywood base with rope pulley system.

Sand pits near Sevenoaks. The mortar achieved a basic 1:3 mix of lime to sand. The mortar constituents were measured out for mixing in tubs to produce consistency. The brick selected was an Ibstock Arundel yellow multi stock, with a published water absorption of 14 per cent - that is average for a house brick. The aim was to replicate to an extent the kind of brickwork common to nineteenth century Victorian terraced properties. I certainly used not a teaspoon of ordinary portland cement in the mix. London tap water was used in the mixing. This test can be repeated by others using the same or similar materials.

The pier was built nine courses high. Working with no time pressure it was of course easy to achieve a very beautifully and solidly built pier. The pier was built in the winter of 2005, but tests did not begin till spring of 2009. The testing was carried out in a private unheated covered workshop.

The pier was built off a plywood base so it could occasionally be lifted up by a traditional rope pulley system for weighing (Figure 1). The author believed there to be advantages in just testing a single pier, enabling more measurements to be taken and observations made than for multiple piers.

\section{Expectations of the test}

If it is accepted that rising dampness must be sourced from below the ground, then a masonry pier standing in a tray of water is not able to produce 'rising damp' - as clearly not a drop of the moisture will have come from the ground. However, this test should certainly offer insight into the potential for moisture to rise up solid masonry, for example where there is a severe water load at the base of an external wall, such as in a low-level penetrating damp scenario. From past dampness investigations the author expected moisture to rise in the masonry more than just within the first course or two of bricks, but had not previously carried out any formal testing. Electronic thermo-hygrometers were known by the author to offer a reliable indication of dampness in solid materials, as he 
had tested them in masonry and mortar screeds in the past. Some of these results can be found published in Remedying Damp, Chapter 8 (Burkinshaw, 2009).

\section{The moisture rise checks}

A range of checks for moisture rise were made on the front side of the pier (shown in Figure 1).

A Protimeter humidity sleeve was fitted into each $16 \mathrm{~mm}$ diameter hole at second, third, fourth, fifth and eighth bed joints. The sleeves would accept a tapered sleeved electronic thermo-hygrometer ('hygrostiks').

It was planned to tabulate the following checks at regular intervals:

1. using thermo-hygrometers at second, third, fourth, fifth and eighth mortar bed joints: Record Equilibrium Relative Humidity (ERH), hole temperature, hole dew point;

2. pin probe damp meter readings at each brick and mortar course;

3. capacitance meter readings at each brick course;

4. surface temperature at brick and mortar bed joints;

5. workshop relative humidity, air temperature and dew point;

6. height of tray water;

7. estimated height of moisture rise on basis of the above measurements taken;

8. weight of pier;

9. amount of water added;

10. visual observations and other comments.

Test Commencement Five litres of rainwater was poured into the tray on 16 March 2009. The rainwater was collected from a diverter fitted into the workshop's rainwater pipe. Water was topped up from time to time when needed to make up for water loss owing to take up by the pier and nominal evaporation of the tray water and off the pier itself. The air dry pier weighed $51.1 \mathrm{~kg}$ just before the tests began.

\section{Test results}

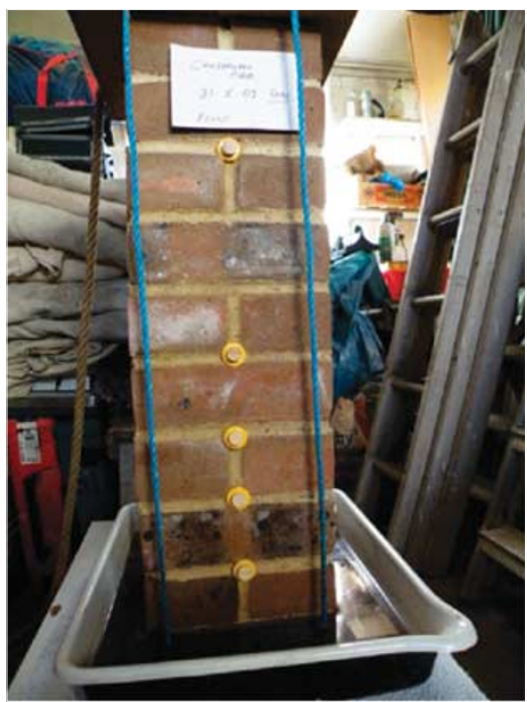

Changes observed to the pier

16.3.09 to 11.5 .09

After 55 days, you may note mortar joints have darkened markedly up to the eighth bed joint. The bottom two brick courses were noticeably wet just two days into the testing.

All the ERH test positions started on March $16^{\text {th }}$ with readings between $\mathrm{RH} 75.4 \%$ - $\mathrm{RH} 77 \%$ - ie typical of quite dry mortar.

By May $11^{\text {th }}$, all ERH positions registered readings of $96-100$ - confirmation of significantly damp masonry at depth.

Figure 2: Appearance of the pier with moisture to the eighth brick. 


\section{Height of rise}

It is not possible to give an exact height in millimetres, because the test methods checked dampness on brick courses and mortar beds. Moisture rose up in the pier to the eighth brick - a height of approximately $600 \mathrm{~mm}$.

The appearance of the pier had changed dramatically (Figure 2).

'ERH' or Equilibrium Relative Humidity (see Figure 3) - A stable RH reading obtained using an RH sensor sealed into a drilled hole. For this, test sensors were sealed in humidity sleeves for exactly $30 \mathrm{~min}$ for a reliable $\mathrm{RH}$ to be recorded. See Remedying Damp for test method explanation.

\section{Moisture rise graph analysis}

The five sensors (hygrostiks) you have seen in Figure 2 registered the increasing moisture content of the brick pier at depth.

By as early as 1 day into the testing, the two bottom brick courses became visually wet, with the ERH readings of the first two sensors soon rising to 100RH. By day 3, two days into the testing the third sensor followed suit. So at the arrowed position at $18 \mathrm{March}$, the bottom three sensors have all by then registered a 100 per cent ERH, meaning the masonry at that level is significantly damp. By 23 March, 6 days into the testing the fourth sensor in bed joint 5 rose to 100 per cent ERH. There was a longer wait, till 20 April, that is 34 days on, when the top sensor in the eighth mortar bed up registered a 95.8 per cent $\mathrm{RH}$ reading.

This reliable ERH evidence of moisture rising within the masonry was mirrored by gradual darkening of the lime mortar bed joints up the pier, increases in capacitance meter readings of brick courses, and of course the sheer increase in the pier's weight. By 20 April, after sitting in a watery tray for 35 days, all sensors had achieved ERH readings in the 96-100 per cent range, after all having begun the test with ERH readings of 75.4-77 per cent - indicative of fairly dry masonry.

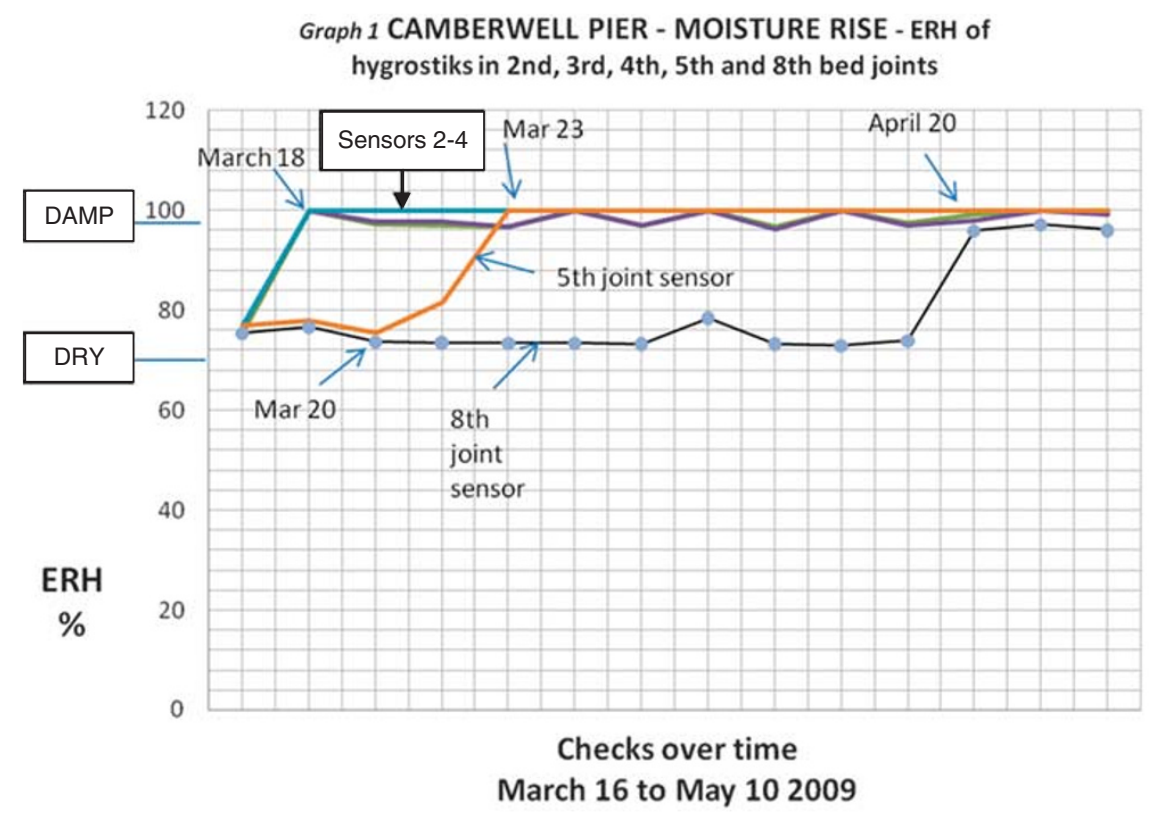

Figure 3: Moisture rise graph. 
Table I: Capacitance meter and pin probe checks at beginning and end of moisture rise test

\begin{tabular}{|c|c|c|c|c|c|}
\hline & \multicolumn{2}{|c|}{$\begin{array}{l}\text { Beginning of moisture } \\
\text { rise test (16 March 2009) }\end{array}$} & \multicolumn{2}{|c|}{$\begin{array}{l}\text { End of moisture } \\
\text { rise test (10 May 2009) }\end{array}$} & \multirow[t]{2}{*}{ Notes } \\
\hline & $\begin{array}{l}\text { Capacitance } \\
\text { meter reading }\end{array}$ & $\begin{array}{l}\text { Pin probe } \\
\text { reading }\end{array}$ & $\begin{array}{l}\text { Capacitance } \\
\text { meter reading }\end{array}$ & $\begin{array}{l}\text { Pin probe } \\
\text { reading }\end{array}$ & \\
\hline 9th brick course & 94 & 10 & 63 & 12.4 & No change \\
\hline 9th bed joint & - & 14.6 & - & 12.4 & No change \\
\hline 8th brick course & 121 & 12.3 & 128 & 21.9 & $\begin{array}{l}\text { Marginally damper } \\
\text { (ERH rise from } 75.4 \% \text { to } 96 \% \text { ) }\end{array}$ \\
\hline 8th bed joint & - & 15 & - & 21.9 & Bed joint now damper/darker \\
\hline 7th brick course & 111 & 10.3 & 166 & 9.3 & $\begin{array}{l}\text { Significant change in capacitance } \\
\text { readings from moisture take-up }\end{array}$ \\
\hline 7th bed joint & - & 13.9 & - & 53 & Damper/darker \\
\hline 6th brick course & $|3|$ & 11.6 & 260 & 14 & Damper \\
\hline 6th bed joint & - & 12.5 & - & 100 & Damper/darker \\
\hline 5 th brick course & 103 & 11.3 & 202 & 10.4 & Damper \\
\hline 5th bed joint & - & 14.9 & - & 82.2 & Damper/darker \\
\hline 4th brick course & 103 & 10.8 & 445 & 20.3 & Damper \\
\hline 4th bed joint & - & 15.5 & - & 59 & Damper/darker \\
\hline 3rd brick course & 97 & II & 533 & 34 & Damper \\
\hline 3rd bed joint & - & 100 & - & 100 & Damper \\
\hline 2nd brick course & 134 & 11.8 & 570 & 35.7 & Wetter/darker \\
\hline 2nd bed joint & - & 65 & - & 100 & Damper/darker \\
\hline Ist brick course & 124 & 9.6 & - & 39 & Wetter/darker \\
\hline Ist bed joint & - & - & - & - & Wetter/darker \\
\hline
\end{tabular}

Note: Bed joints not checked till 18 March 2009.

At the beginning and end of the test capacitance meter readings of brick courses and bed joints can be compared (see Table 1). Mortar bed pin probe checks did not commence till 2 days into the testing. Damp meter readings can give a useful indication of a moisture rise in masonry, especially in capacitance mode.

Analysis: As you can see from the checks in Table 1 capacitance meter readings on bricks at the beginning of the testing were all low - 94-134. By the end of the testing readings had risen significantly up to seven courses up the pier.

For some reason pin probe readings of mortar bed joints were not taken till 18 March, when lower bed joints had already become very damp from 2 days in tray water. From then on, all joints registered progressively higher pin probe readings up to the eighth course - as the initially dry white lime mortar joints gradually changed to a grey colour. Readings were taken for most weeks. Pin probe readings offer an indication only of dampness, with capacitance meter readings more reliable, ERH readings in drilled holes yet more reliable (see Figure 3).

\section{Speed of rise of moisture}

After the first 14 min under test, water was seen to have soaked completely the first brick course - that is $5 \mathrm{~mm}$ per min. Just over a day into the test, moisture had risen $200 \mathrm{~mm}$ corresponding to an average speed of $6.5 \mathrm{~mm}$ per hour. The speed slowed for the last few weeks to as slow as $8 \mathrm{~mm}$ per day. The overall height of $600 \mathrm{~mm}$ took 45 days.

\section{Other findings}

By the end of the test phase on 10 May, the pier had increased in weight from 51.1 to $57.8 \mathrm{~kg}$.

Nominal condensation was confirmed using the Protimeter 'condensator' facility when the surface temperature of the bottom brick courses dropped twice in March and once in April, a fraction below dew point. This would not have amounted to a significant moisture contribution. 
The light dusting of efflorescence developing on the masonry face is unlikely to have attracted any significant moisture from the air by virtue of its hygroscopic properties.

\section{INJECTION CREAM DPC EFFECTIVENESS TEST ON CAMBERWELL PIER}

\section{Setting up the cream injection}

\section{PH testing of mortar bed}

Just before injecting one mortar bed with damp proofing cream, the mortar was tested by the writer for acidity. The mortar bed joint registered PH 9-11. A mortar sample was also tested by the cream manufacturer who confirmed a PH of 11.8. Alkalinity of $12+$ might not suit the particular cream, therefore always consult manufacturers.

\section{The cream injection}

The injection cream used is silane/siloxane with 64 per cent active ingredient. Two $12 \mathrm{~mm}$ diameter holes were drilled out in the fourth mortar bed joint using a new $300 \mathrm{~mm}$ length drill bit. Each hole was $185 \mathrm{~mm}$ deep. The cream was injected into the two holes using the cream manufacturer's impressively engineered applicator gun (Figure 4). The cream is sold in plastic cartridges that are slit at the top when fitted into the gun. Application of the cream is very easy - requiring just the gun and a powerful masonry drill. The actual amount of cream injected for this test was very carefully monitored, with the injection gun and cartridge weighed before and after the application to confirm the amount of cream actually injected into a hole of known volume. The injection was actually assisted by the manufacturer's research and development manager. This was arranged to be absolutely sure the chemicals were introduced correctly, and also that the reliability of the testing procedure would be respected by the product manufacturer and the wider industry . It is probably more logical to inject mortar joints than the bricks themselves as joints provide the continuous road upwards for moisture. The injection should produce a modified damp-resistant mortar bed joint.

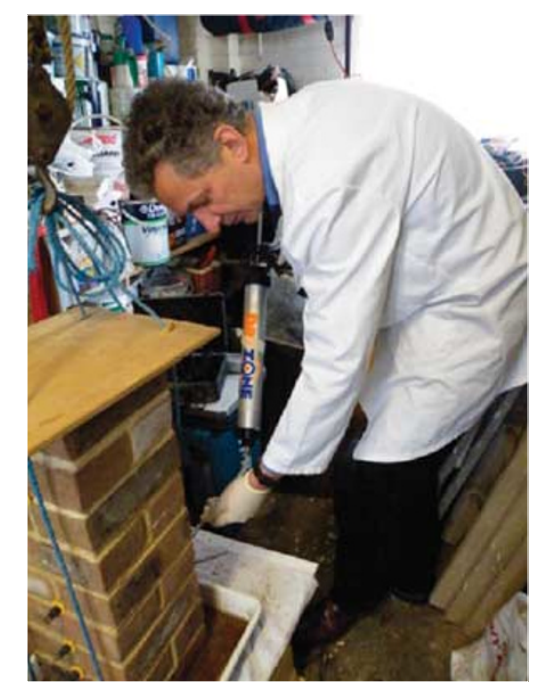

Figure 4: Injection dpc cream is gunned into the fourth mortar bed joint. 


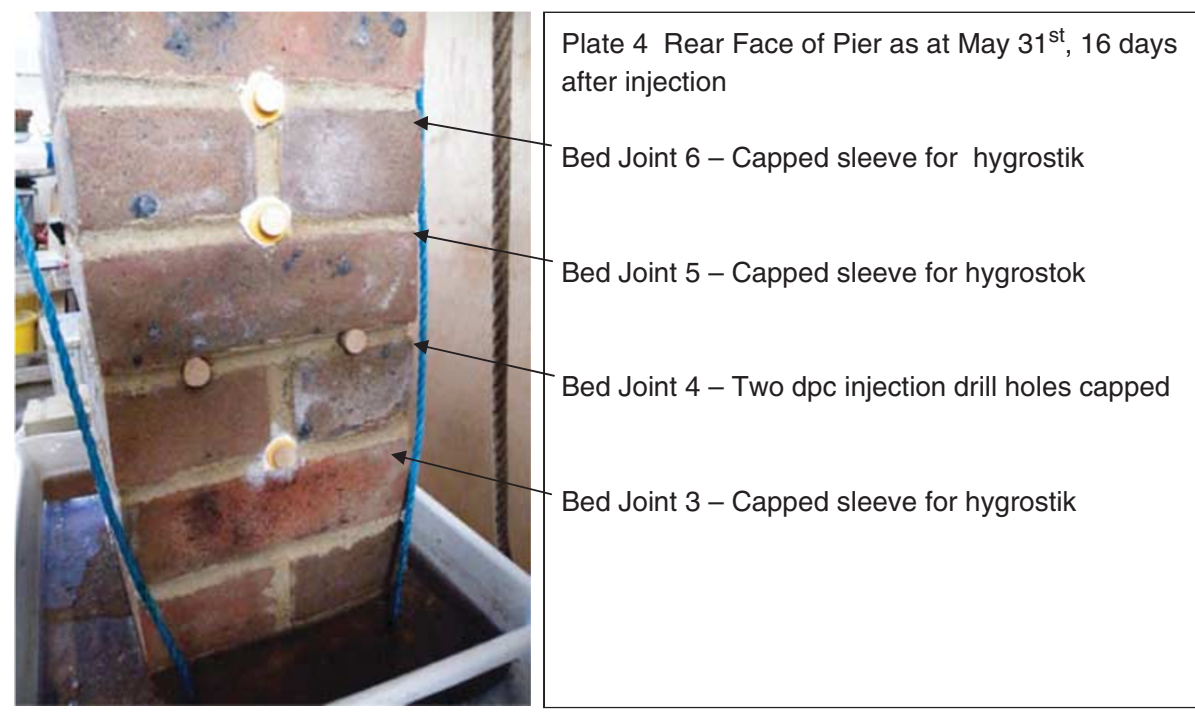

Figure 5: DPC injected on the rear face of the pier, in the fourth bed joint up.

\section{Expectations of the test}

The aim of the dpc injection test was certainly not to attempt to prove that the injection of a modern patent cream to produce a dpc would not succeed. The masonry pier was very carefully and solidly built, so a very reliable take up of the chemical should be achieved. The injection itself was most carefully carried out and a very adequate dosage of the cream was introduced. The test was very severe.

In Table 2 it may be noted that this test is titled up as 'phase 1'. This is because the dpc effectiveness test is ongoing and will be next reviewed/reassessed probably in 2011. This article therefore assesses performance to the end of Round 1.

\section{Test positions}

The dpc was injected on the rear face of the pier, in the fourth bed joint up - as shown in Figure 5.

Mortar drilled out for the injection on the fourth bed joint was carbide tested to determine moisture content.

Sleeve test positions were drilled out in the third, fifth and sixth bed joints. Extracted mortar drillings were carbide tested to ascertain moisture content.

\section{Damp course test results}

Interestingly, after a 9-month test period (and the tests are still ongoing) the weight of the pier dropped from 57.8 to $54.7 \mathrm{~kg}$ - that is a loss of $3.1 \mathrm{~kg}$. The pier's total weight could not drop to the weight of the air dry pier (that is $51.1 \mathrm{~kg}$ at the very beginning of the testing back in March 2009), because of course the dpc is in the fourth bed joint up, so the bottom brick courses will obviously remain wet in a tray of water whether the dpc is working or not.

\section{Analysis of ERH graph (Figure 6)}

Sixth bed joint (second bed joint above new dpc) ERH dropped from 92.6 to 75.9 per cent, again confirming that masonry above the new dpc had become drier. Carbide tests moisture content $(\mathrm{mc})$ had confirmed a drop in mc from 5.6 per cent to 0.6 per cent. 


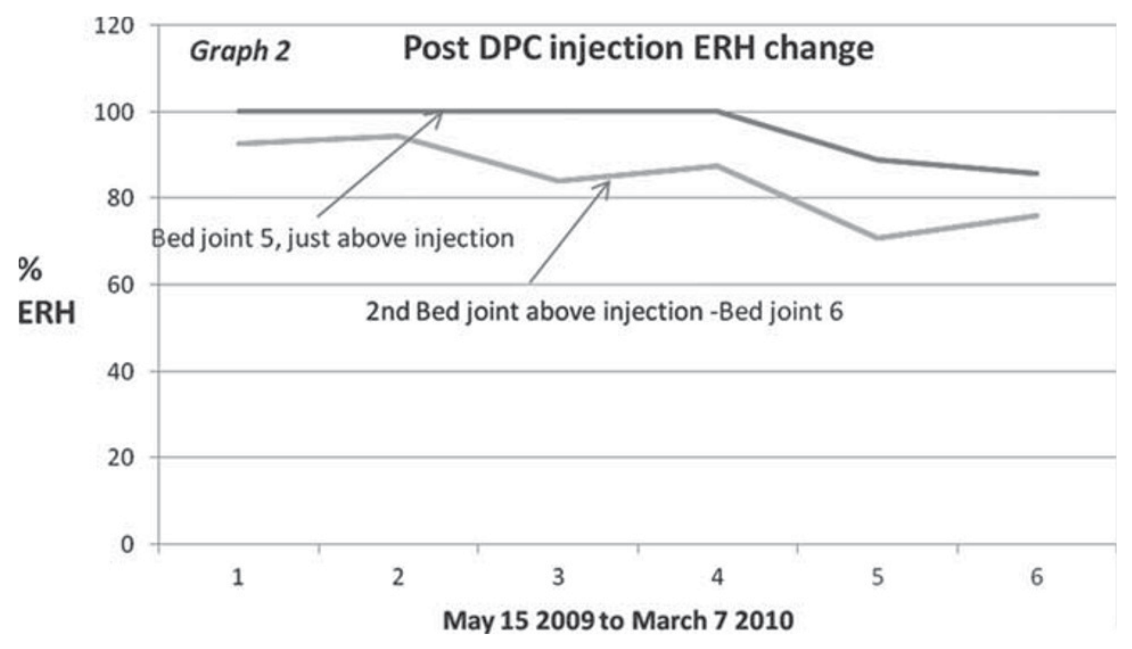

Figure 6: Post DPC : ERH reduction graph.

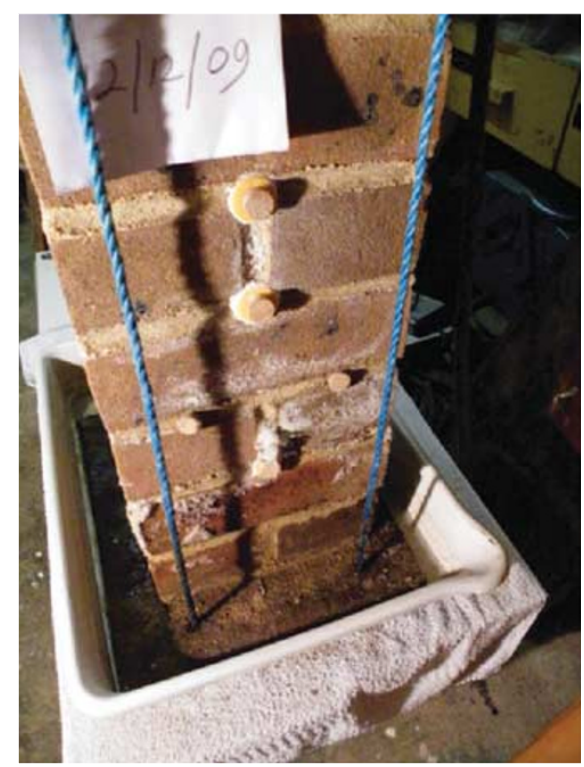

By December 2009 the rear face of the dpc injected pier (and other pier faces too) shows considerable efflorescence mainly to mortar joints both above and below the injected mortar bed.

Figure 7: Injected mortar bed.

Fifth bed joint (bed joint above new dpc) - The sensor in the bed joint just above the injected dpc is probably the most important to study. The ERH reading of 100 per cent just before the injection on 15 May 2009 showed that bed joint to be significantly damp in fact confirmed to have a moisture content of 7.8 per cent. At the end of the test phase, the ERH of the bed joint just above the new dpc had dropped to 85.8 per cent and as Table 2 shows its moisture content to have reduced down to 0.7 per cent.

In the author's experience, ERH often needs to be in the 90 per cent plus range to mean a material is significantly damp.

It must be noted that the humidity sleeves were plugged between test. For taking the ERH reading, the hygrostiks were sealed into the sleeves for exactly $30 \mathrm{~min}$. The hygrostiks were labelled so the same hygrostik was always used in the same sleeve hole (Figure 7). 
Table 2: Carbide meter tests of Camberwell Pier bed joints at beginning and end of phase I of DPC test (checks on rear pier face)

\begin{tabular}{|c|c|c|c|c|c|}
\hline \multicolumn{3}{|c|}{ Testing on 15 May 2009 before DPC injection } & \multicolumn{3}{|c|}{ Testing on 4 March 2010 at end of DPC test } \\
\hline Bed joint & Notes & Carbide test & Bed joint & Notes & Carbide test \\
\hline 6th & - & $5.6 \%$ & 6th & - & $0.6 \%$ \\
\hline 5 th & - & $\begin{array}{c}7.8 \% \\
(\mathrm{ERH} \mathrm{I00)}\end{array}$ & 5 th & $\begin{array}{c}\text { Ist bed joint above } \\
\text { DPC }\end{array}$ & $\begin{array}{c}0.7 \% \\
(\text { ERH } 85.8)\end{array}$ \\
\hline 4th & Injected DPC bed joint & $7.2 \%$ & 4 th & DPC joint & $0.4 \%$ \\
\hline $3 r d$ & - & $9 \%$ & $3 r d$ & Bed joint below dpc & $8.6 \%$ \\
\hline 2nd & - & - & 2nd & - & - \\
\hline Ist & - & - & Ist & - & - \\
\hline WATER & - & - & WATER & - & - \\
\hline
\end{tabular}

\section{Carbide test results}

Carbide tests in monitoring are for me the 'gold standard' of moisture content tests.

It was not possible to carry out dozens of carbide meter tests of drilled samples, because of the size of the pier under test, and therefore I restricted my carbide tests to 'before and after' tests.

Some critical drilled samples were double checked for moisture content by both carbide testing and oven drying - with comparable results obtained (Table 2).

\section{Analysis of carbide testing}

The tray water was topped up regularly to give the dpc a continuous high water load to cope with. As can be seen, the moisture content of the brickwork just below the dpc had almost the same moisture content at the end of the test as at the beginning, with 8.6 per cent on 4 March 2010, showing the bed joint was very damp verging on almost wet till the end of the testing phase. With this amount of moisture present, the mortar would adhere to the drill bit as a paste during the drilling.

There is a very dramatic drop in the moisture content of the first bed joint above the dpc - from 7.8 per cent down to 0.7 per cent. Because the sand/lime mortar is quite easy to drill out, the moisture in the drillings will not have been very much affected by drill bit heat - so all the carbide meter readings would fairly accurately reflect the actual amount of moisture lurking deep in the bed joints.

Note also that the second bed joint above the dpc has also pretty much dried out thanks to the new dpc - dropping in moisture content from 5.6 per cent to 0.6 per cent.

To appreciate the significance of moisture content of common construction materials please consult Table 3 (p. 89) in Diagnosing Damp.

For interest, I have shown how ERH readings for the bed joint above the dpc dropped from $100 \mathrm{ERH}$ to $85.8 \mathrm{ERH}$.

Although not a reliable indicator of drying at depth, pin probe readings to the bed joints above the dpc all declined from maximum 100 relative readings to readings ranging from 15.5 at the dpc bed joint, and to 19.9 at the first bed joint above - again an indication at least that mortar joints had dried down after the dpc injection.

During the post dpc injection phase the bottom five courses of masonry developed much efflorescence, with mould spotting also having developed during the test period mainly to the two bottom brick courses. A flurry of efflorescence is usually an indication of significant drying.

On one occasion, Monday 11 January - it was noted that ice had formed in the tray. 


\section{CONCLUSIONS}

\section{On moisture rise in masonry}

(i) Moisture was confirmed to rise approximately $600 \mathrm{~mm}$ in the brick pier. And generally:

(ii) The speed of rise was fastest at the beginning of the testing.

(iii) The pier also experienced some nominal condensation on several occasions, plus salt deposition and also some limited surface mould growth.

(iv) The rise of moisture was most evident to the visibly wetted up bottom two courses, but was also visually evident as mortar bed joints darkened as the dampness rose.

(v) Such a test does not prove or disprove 'rising damp', or attempt to replicate it, but shows how a masonry pier subjected to a considerable water load at its base can take up moisture to a significant height.

(vi) Specialist mortars are not needed to create a significant rise of moisture in a brick pier. For this test a simple 1:3 sand/lime mix was used. Cement mortar would probably also produce a significant moisture rise, as I have found from past materials tests that standard cement/sand mixes (for example 1: 4 or 1:5) are quite absorbent (see Table 3 (p. 89)) of Diagnosing Damp.

(vii) Although just the bottom two brick courses may appear visually darkened/wetted, or wet to touch, significant dampness will have risen higher unseen within the masonry, detectable by various measuring techniques.

(viii) Moisture was found to be rising faster via brick mortar jointing, meaning that the main pathway upwards for moisture was in the joints rather than via bricks. Darkening of the white lime mortar joints flagged up dampening of joints higher and higher up the pier as moisture rose.

(ix) If pier brickwork were coated with impervious paints or renders then one would expect moisture to rise higher because of the effect of reduced evaporation off the pier face - and of course a higher pier would have been needed to track a higher moisture rise.

(x) It is likely that in time, moisture would have slowly risen yet higher up Camberwell Pier.

\section{On effectiveness of injected cream DPC}

(i) By the end of the test period, moisture in the pier to the injected bed joint and masonry above had very markedly reduced - for example a reduction in mc of bed joint above the dpc from 7.8 to 0.7 per cent.

And generally:

(ii) This particular damp proof injection was carried out very carefully and methodically, with exactly the right amount of cream injected into the holes of known depth and diameter. One would expect the effectiveness of the cream dpc to depend, of course, on correct amount of cream introduced into the drill holes.

(iii) The percentage of 'active ingredient' in the selected injection cream may have a bearing on its efficiency.

(iv) The mortar bed joints were tested to ensure the $\mathrm{PH}$ was suitable for satisfactory curing and life expectancy of the injection chemicals. A very high PH of say 12-14 could, I am informed, possibly reduce effectiveness of the dpc. 
(v) This test does not give any indication whatsoever concerning how long the injection might be effective for.

(vi) This test is, in the author's opinion, far more severe than the standard BBA test procedure, where a high water load is not maintained at the base of the test pillar during the whole test period. One can have a greater confidence in a dpc system capable of coping with high water load.

(vii) This test phase was carried out completely independently of all potentially interested parties, and none of the testing received funding.

(viii) Although some efflorescence occurred to brick faces during the initial test phase, a much greater salt proliferation was noted during the post dpc phase, indicative of drying out.

(ix) The testing is ongoing. Should the new dpc show any sign of failing over course of the next year I will be publishing a follow-up paper.

\section{IMPLICATIONS OF THE CAMBERWELL PIER TESTING}

The fact that an injected cream dpc method worked very well in the test pier has no bearing whatsoever on whether it is always or ever the best remedy option for walls subject to significant wall base damp. As explained earlier, most wallbase damp problems I have investigated are driven by low-level penetrating dampness - and other remedies often offer a better long-term cure.

The test pier was very solidly built, and most walls the author has surveyed and indeed dismantled are nearly always full of voids, which might affect the take-up of the chemicals and effectiveness of this dpc method. Furthermore, the cream for Camberwell Pier was injected extremely carefully, and this may be much more difficult to achieve on a construction site. Economic factors may limit the volume of cream injected into drill holes, thereby compromising dpc effectiveness.

It must be remembered that low-level damp penetration could easily defeat any horizontal band of treated masonry, by soaking laterally through the porous masonry above or below the injected dpc. (see Burkinshaw (2009) in which a 'ledge effect' is first defined and explained).

Importantly the dpc injection of Camberwell Pier is working.

A cream injection dpc such as used for Camberwell Pier is surely a useful dampproofing method to add to the armoury, and could have a lead or support role where (particularly) a vertical moisture movement needs to be controlled. You may consider specifying cream injection to damp course an old chimney - or a roof parapet wall. It can of course be used in tandem with other methods to help control unwanted dampness.

\section{REFERENCES}

BBC2. (1999) Raising the roof: Rising damp. BBC2, Shown 1999.

Trotman, P., Sanders, C. and Harrison, H. (2004) Understanding Dampness. BRE Bookshop.

BRE. (2007) BRE Digest 245: 'Rising Damp in Walls - Diagnosis and Treatment', P. Trotman (ed.) Garston, Watford: BRE Press.

Burkinshaw, R. (2009) Remedying Damp. Coventry, UK: RICS-Royal Institution of Chartered Surveyors Books.

Burkinshaw, R. and Parrett, M. (2003) Diagnosing Damp. Coventry, UK: RICS-Royal Institution of Chartered Surveyors Books. 
Coleman, G. (1990) Guide to Identification of Dampness in Buildings. Wessex Publishing. Hollis, M. (2005) Surveying Buildings, 5th edn. Coventry, UK: RICS-Royal Institution of Chartered Surveyors Books. Melville, I.A. and Gordon, I.A. (1988) The Repair and Maintenance of Houses. The Estates Gazette Ltd, 1988 edn. Oxley, T.A. and Gobert, E.G. (1989) Dampness in Buildings, 2nd edn. Oxford: Butterworth Heinemann, Revised 1989.

\section{FURTHER READING}

Burkinshaw, R. (2005) Wall base damp - Is one horizontal damp proof course sufficient protection? Journal of Building Appraisal 1(1): 7-19, Currently available on internet as free download. 